\title{
The Influence of Advertising Appeals on Consumers' Willingness to Participate in Sustainable Tourism Consumption
}

\author{
Hui Zhang $\mathbb{D}^{1}$, Yupeng Mou $\mathbb{D},^{2}$ Tao Wang $\mathbb{D}^{3}$, and Jia Hu $\mathbb{D}^{1}$ \\ ${ }^{1}$ School of Economics and Management, Hubei Engineering University, Xiaogan 432100, China \\ ${ }^{2}$ School of Management, China University of Mining and Technology, Xuzhou 221000, China \\ ${ }^{3}$ School of Economics and Management, Wuhan University, Wuhan 430072, China \\ Correspondence should be addressed to Hui Zhang; zhanghui@hbeu.edu.cn and Jia Hu; 705260303@qq.com
}

Received 17 August 2020; Revised 19 September 2020; Accepted 6 October 2020; Published 29 October 2020

Academic Editor: Jun Yang

Copyright ( $\odot 2020$ Hui Zhang et al. This is an open access article distributed under the Creative Commons Attribution License, which permits unrestricted use, distribution, and reproduction in any medium, provided the original work is properly cited.

\begin{abstract}
Sustainable consumption has attracted much attention from the tourism industry. However, from the perspective of academic research, the psychological mechanism of collaborative consumption has not been thoroughly understood as the main form of sustainable consumption. This study explores the impact of advertising appeals on consumers' willingness to participate in collaborative consumption. Through two psychological experiments, it is believed that, relative to the rational appeal, the emotional appeal will positively affect consumers' participation willingness to collaborative consumption, and psychological ownership mediates this relationship. Furthermore, the form of information presentation moderates the influence of advertising appeals on psychological ownership.
\end{abstract}

\section{Introduction}

While the sharing economy craze remained unabated in 2017, collaborative consumption in the business world staged a song of ice and fire after 2019. Even though leaders in the Chinese tourism industry such as Tujia Homestay and Huazhu Hotels Group have accelerated the timeshare tourism business, the industry is still full of chaos and disputes [1]. While Mobike rapidly developed in the field of bike sharing locally and abroad, Wukong Bike and 3Vbike ceased operations one after the other [2]. There are different explanations for this complicated business situation, which generally include the choice of profit model, change in national policy, and management and control of company operation [3]. In the context of a sharing economy, consumers can directly participate in collaborative consumption. Knowing that the degree of participation mainly depends on the intention of consumers, this study examines the factors that affect consumers' willingness to participate in collaborative consumption.
This research also aims to analyze the role of psychological ownership in the process of collaborative consumption. As an important sustainable consumption model, collaborative consumption refers to consumption based on the right of use. In contrast to ownership consumption, it reduces consumer costs, especially consumption responsibilities, for products or services [4]. The form and process of collaborative consumption also determine that consumers will focus on meeting individual needs and repeatedly interact with companies, from passive consumption service to active participation and responsibility [5]. This enhances consumers' psychological ownership of products or services [6]. Furthermore, psychological ownership strengthens the participation tendency of consumers and avoids negative behaviors similar to damaging shared products [7]. From the perspective of communication between companies and consumers in a sharing economy, social media advertisements of collaborative consumption companies mostly emphasize the functional value of convenience and saving on products or services. Its prosocial emotional characteristics, such as environmental protection, sustainable 
development, and building intimate relationships, are also highlighted [8].

Sharing is the most basic form of communication in human economic behavior, which can be traced back to tens of thousands of years ago [9]. However, it has not received much attention from tourism research [10]. There are two main reasons for consumer participation in collaborative consumption. One is convenience and price from the utilitarian perspective, and the other is environmental protection and sustainable development from the perspective of self-extension [11]. Compared with market practices, collaborative consumption has not been thoroughly understood, and the mechanism of consumers' participation in collaborative consumption remains unclear [12]. There are also no specific operational opinions on how to carry out collaborative consumption models [11, 13]. From the viewpoint of the rapid development of sharing economies, there are still many problems that need to be further examined in the field of collaborative consumption, including its influencing factors $[14,15]$ and the change of psychological ownership and marketing consequences [16, 17].

This paper aims to explore the influence of different advertising appeals and information types on consumers' collaborative consumption intentions. It also analyzes the mediating effect of psychological ownership on the above relations by combining the development status of sustainable consumption.

\section{Literature Review and Hypotheses Development}

2.1. Collaborative Consumption. Collaborative consumption is when consumers coordinate the acquisition and allocation of resources for consumption in exchange for some form of compensation [18]. In the context of a sharing economy, it has become the main form of sustainable consumption. Collaborative consumption usually occurs within organizations or communities, where participants allocate goods, services, travel plans, venues, and even money in the form of leasing, lending, exchanges, and transactions [13, 18, 19]. There are two factors that affect consumers' participation in collaborative consumption. The first is that they are driven by utilitarianism. Consumers who participate in collaborative consumption can obtain direct economic benefits through factors such as function and convenience. These economic benefits are the main factors driving consumers to participate in plans of car sharing, bike sharing, and call time sharing of mobile phones [20]. The lack of perception of economic interests will hinder consumers' participation in this form of consumption [21]. Collaborative consumption provides more value when consumers pay less $[19,20]$, making the sharing economy more attractive since its benefits are greater than the costs [22].

The second factor is the pursuit of prosocial value. Collaborative consumption can reduce the consumption of new products and raw materials, which is conducive to environmental protection $[19,23]$. It enables participants to establish and maintain social contact with others by cooperating with social networks, direct peer-to-peer interaction, and personal experience sharing. Participation in collaborative consumption provides a platform for making new friends and developing valuable relationships [19]. This platform not only helps strangers meet and communicate online, but also provides opportunities for personal offline communication. For example, community building, antimaterialism, and voluntary behavior will affect the sharing behavior of consumers in toy houses and tourism events [24, 25]. Having a sense of pleasure and consumption sustainability will also have a significant effect on the behavior tendency of collaborative consumption [26].

Compared with the transaction of goods or services, the development of collaborative consumption benefits from the recent advancement of internet technology, which is an emerging market phenomenon. However, empirical studies on the influencing factors of participating in collaborative consumption are rare, and the psychological mechanism of participation has not been deeply explored [13].

2.2. Advertising Appeals. Advertising appeals refer to different types of interests or information that appear when communicating with consumers [27]. Persuasive information needs to adopt appropriate appeals and provide information related to emotion, desire, or rationality and operability in order to communicate with potential consumers [28]. Advertising appeals can be divided into emotional and rational appeals [29]. Emotional appeals strive to convey the pleasant feeling of the product, which is related to soft marketing appeal, and emphasize the emotion [12], that is, the emotion and subjective impression of the product's tangible characteristics [30]. Rational appeals show how the product works, tell consumers the actual interests, and regard the product itself as the purpose. The information it provides is more focused on the use and description of a product, which is related to hard marketing. The two kinds of appeals differ in terms of method and purpose [31]. When the advertisement focuses on the emotion or desire achieved by the product, it emphasizes the high-level goal of why it should be purchased. When it focuses on rationality or operability, it emphasizes the functions of the product.

The background of collaborative consumption and that of common consumption differ mostly in two points. The first is the emergence of prosocial value. The second is that there is no transfer of ownership. Emotional appeals are more closely related to the values emphasized by collaborative consumption for consumers, making them more likely to accept related products or services. From the market reality, when consumers choose to share products or services, the recognition of values is also the selling point of many products. When there is no transfer of ownership, consumer involvement becomes relatively weak, so they are reluctant to invest too much cognitive effort in the selection process. Emotional appeals do not need much detailed processing because they only present more general information, such as limited product features [32]. In contrast, rational appeals contain a lot of functional parameters and information on features, so more cognitive effort should be 
mobilized towards understanding them [33]. Therefore, compared with theoretical appeals, emotional appeals are more consistent with collaborative consumers, which will positively affect the intention of consumers to participate:

$\mathrm{H} 1$ : in the context of collaborative consumption, emotional appeal advertising will positively affect consumers' willingness to participate, compared with rational appeal advertising.

\subsection{Psychological Ownership. Psychological ownership re-} fers to a state in which a person feels that he or she owns the target object or a part of it [13]. It originates from the extension of the concept of "I" in psychology. People's sense of ownership or the experience of psychological possession is not limited to actual possession [31]. There are three main motivations of psychological ownership: efficacy, selfidentity, and owned space [34]. For the pursuit of efficacy, people control the environment and objectives by gaining disposal power to obtain ideal results. For the promotion of self-identity, people are mainly through the self-involvement in the process of pursuing goals and personal identification of the goal concept. For owned space, emotional connection and pride are mainly formed through familiarity with the subject matter [35].

Collaborative consumption does not advocate ownership, believing that it bears the responsibility of use, maintenance, and disposal. However, in practice, the relevant liability caused by ownership or violation loss is only reduced in the collaborative consumption scenario, but does not disappear. For example, in the process of collaborative consumption, consumers have the responsibility to use products or services reasonably to ensure that other consumers can use them smoothly. Sanitation, delivery, and other links need to be carried out according to relevant requirements. Although physical ownership has not been transferred, psychological ownership does not disappear and still exists.

The emotional appeal will emphasize the values of collaborative consumption, such as environmental protection, literature, and art, among others. It makes it easier for consumers to form self-related meanings and situations and increase their sense of identity for collaborative consumption. It is easier to enhance the consumer's involvement in identity goals and strengthen the relationship between consumers and collaborative consumption, thus strengthening psychological ownership [36]. The rational appeal lays more emphasis on the efficacy of products or services. In the context of collaborative consumers, the sense of efficacy is not well supported by entities, and the power of control or disposal is weakened. Relatively speaking, it has a small impact on psychological ownership. Emotional appeal advertising involves values and emotions, which will have a greater impact on the identity of consumers associated with it. Consumers will attach more importance and become more willing to "own" it [37]. Accordingly, the following hypothesis is proposed:
$\mathrm{H} 2$ : compared with rational appeal advertising, emotional appeal advertising has a positive impact on consumers' psychological ownership of collaborative consumption products or services.

It is generally believed that psychological ownership has a positive effect on consumer behavior [17]. As the promotion of psychological ownership will strengthen the idea that products or services become an extension of the self, it will be easier to resist the impact of competitive brands. Psychological ownership will enhance word of mouth and brand loyalty. In the process of collaborative consumption, it will reflect more important consumption significance without the transfer of entity ownership, which will directly affect the choice of consumers. Research in the field of organization also believes that the psychological ownership of the organization will enhance employees' citizenship behavior, strengthen their commitment to the organization, and reduce turnover rate. At the same time, due to the strengthening of psychological ownership, there will be an ownership effect, and individuals will evaluate the "owned" products or services more positively. Therefore, the following hypothesis is proposed:

H3: consumers' psychological ownership of collaborative consumption products or services has a positive impact on consumers' willingness to participate.

Collaborative consumption products emphasize convenience and play down responsibility in the consumption process. This, coupled with the uneven quality of consumers, can damage shared products from time to time, seriously affecting the development of related industries. The key mechanism is that consumers do not have a strong sense of psychological ownership, so they do not feel that they "own" the products or services. The right to use can partly replace ownership. However, from the perspective of company operations, consumers who have no connection with companies and only pay attention to functions are more likely to transfer their affection to other products. In comparison with rational appeals, emotional appeals more easily develop consumers' resonance to product values and emotions, strengthening psychological ownership, and enhancing their willingness to participate. Therefore, the following hypothesis is proposed:

H4: consumers' psychological ownership of collaborative consumption products or services mediates the relationship between advertising appeals and participation intention.

There are many forms of advertising appeals. Since collaborative consumer advertising takes into account more factors, such as prosocial factors and network effects of participants, this study only focuses on two commonly used forms of such advertising: consumer- and company-oriented information [38]. Consumer-oriented information places emphasis on encouraging consumers to participate in products or services and tends to stimulate self-related ideas to help solve social and economic problems [39]. It often uses the form of "Would you like to join us?" and uses the second person point of view to describe the form of shared values and narrative 
appeals. The corresponding company-oriented information mainly conveys the company's practice to the target audience. It often uses the form of "What will we do?" in the first person point of view to show the value of products and services from the perspective of companies [40]. The above communication methods enable the audience to connect information with selfrelated experiences, which is called self-reference [41].

Self-reference can promote the in-depth processing of information and stimulate self-related memory [42]. Consumer-oriented information is more likely to arouse selfreference, which tends to use analytical thinking to process information. In contrast, the correlation between companyoriented information and the self is not high. Consumers will think in a holistic way and not pay attention to specific information [43]. The adoption of consumer-oriented information will strengthen consumers' understanding of emotional appeals, improve the relationship between products or services and the consumer, and further emphasize psychological ownership. Although it also contributes to understanding functional appeals in the context of collaborative consumption, the function of a single product or service becomes weak, and the sense of efficacy is low. Therefore, consumer-oriented information will strengthen the relationship between appeals and psychological ownership. Company-oriented information lays more emphasis on corporate behavior and has a weaker connection with consumers. This makes it difficult for consumers to develop self-identity and will not affect the impact of appeals on psychological ownership. Therefore, the following hypothesis is developed:

H5: the means of expression of collaborative consumption advertising can adjust the relationship between advertising appeal and psychological ownership. That is to say, compared with company-oriented information, consumer-oriented information will strengthen the $\mathrm{H} 2$ relationship.

The topic of this research involves four variables: advertising appeal, psychological ownership, participation willingness, and means of expression. Logic is proposed according to hypotheses. The relevant conceptual framework is shown in Figure 1.

\section{Data and Research Methods}

\subsection{Research 1}

3.1.1. Research Design and Subjects. Research 1 mainly focused on the influence of advertising appeals on consumers' willingness to participate and the mediating effect of psychological ownership. The research adopted the control group experimental method, and the collaborative consumption scenario adopted tourism short rentals. The advertising materials were extracted from actual advertisements of Airbnb, Mayi, and Xiaozhu, and the kind of pictures and words commonly used by these companies was adopted. The main reasons for choosing this scenario are as follows. First, tourism short rental originated before the current boom in the sharing economy and has a more mature industrial development. Second, research 1 involves college students, who represent the key consumer groups of tourism short rentals and have a certain understanding of the short rental mode.

Through campus advertising, the researcher recruited volunteers to test the advertising design effect of the company's homepage. A total of 99 students from a university in Hubei were recruited as participants. After the test, all research participants would receive a gift worth 15 yuan. Among the subjects aged 18 to 26 years old, $37 \%$ were males and $63 \%$ were females. All subjects were randomly divided into four groups, and the experiment was conducted in different rooms within the university. In order to avoid the subjects' discovery of the true purpose of the experiment and affecting its impact, a short fictional rental company named "Woniu" was created. Actual advertising content used by Airbnb, Mayi, Xiaozhu, and Tujia were used to promote "Woniu."

The advertising content of the aforementioned companies could be divided into two categories: function and emotion, which also correspond to the focus of this research, namely, the design of emotional appeals and rational appeals. Among them, there was a lot of advertising content related to price concessions (e.g., "special offer tonight, $30 \%$ discount," "special sale on Thursday, selected beautiful houses, from 5 yuan"). The research did not pay attention to the influence of price and other factors, so content selection did not consider information on price. The content of the functional category mainly included security, credit, housing, and other services (e.g., "perfect security mechanism," "compensation in advance," and " 4 million houses for you to choose"). Emotional content mainly included sharing, exploration, relationship, and other aspects of concern (e.g., "don't go here, live here," "meet with you in another place," and "all the encounters in the world are reunion after a long separation"). The experimental materials were adapted according to real advertisements. The relevant information is shown in Table 1.

To highlight the comparative effect of the experiment, the company name "Woniu" was appropriately enlarged in advertisements emphasizing company-oriented information, while "you" was appropriately enlarged in those emphasizing consumer-oriented information. In advertisements that emphasized emotional appeal, the blue sky, white clouds, green plants, and distant mountains were used as the background. In those that focused on rational appeal, actual pictures of the room were used as the background.

In the experiment, the researcher explained to the subjects that they were recruited to test the design of homepage ads. In the middle of the homepage of Woniu Company's website, one can find its company profile, which briefly introduces the company's development history, main business, scale, and service guarantee.

The related introduction enabled participants to have a basic understanding of the company and provided support for subsequent advertising content testing. Ten seconds after the homepage was opened, a window advertisement with the size of $336336 * 280$ px popped up in the middle of the screen. When the subjects closed the window advertisement 


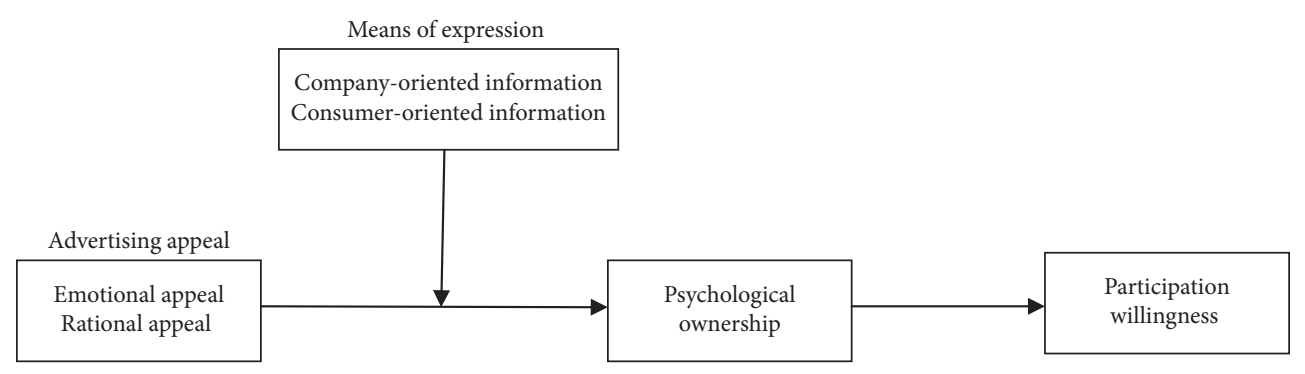

FIGURE 1: Research framework.

TABLE 1: Main text contents of experimental materials (research 1).

\begin{tabular}{lcc}
\hline Type & \multicolumn{1}{c}{ Company-oriented information } & Consumer-oriented information \\
$\begin{array}{l}\text { Emotional } \\
\text { appeals }\end{array}$ & $\begin{array}{c}\text { Woniu provides you with the opportunity to have a good story } \\
\text { with the world. Explore the unknown, meet and experience, } \\
\text { and share freely. }\end{array}$ & $\begin{array}{c}\text { Woniu invites you to have a wonderful story with the } \\
\text { world. Explore the unknown, meet and experience, and } \\
\text { share freely. }\end{array}$ \\
\hline $\begin{array}{l}\text { Rational } \\
\text { appeals }\end{array}$ & $\begin{array}{c}\text { Woniu has selected excellent accommodation for you. } \\
\text { Security mechanism, credit guarantee, and real house supply. }\end{array}$ & $\begin{array}{c}\text { Woniu invites you to appreciate the excellent } \\
\text { accommodation. Security mechanism, credit guarantee, } \\
\text { and real house supply. }\end{array}$ \\
\hline
\end{tabular}

for 10 seconds, the relevant questionnaire appears. In the process of collecting the experimental questionnaires, three were not completed, and a total of 96 valid questionnaires were obtained.

The content of the questionnaire mainly includes research variables, such as psychological ownership and participation willingness, customer knowledge, advertising effectiveness evaluation, and Woniu brand familiarity. These are taken as the control variables. Customer knowledge was taken as a control variable, considering that sharing economy is a new hotspot in market development, and understanding related phenomena will affect participation willingness. The evaluation of advertising effectiveness mainly involves advertising design and expression, and the differences in effectiveness will directly affect participation willingness. The Woniu brand is a virtual one, so it is necessary to avoid the influence of brand familiarity on participation willingness.

3.1.2. Control Test. All the scales used the mature items in the literature. Among them, the five-item scale $(\alpha=0.87)$ [44] was used for the two kinds of advertising appeals, the single-item mode for advertising expression [38], the sevenitem scale $(\alpha=0.83)$ for psychological ownership [45], the five-item scale $(\alpha=0.79)$ for participation willingness [46], the five-item scale $(\alpha=0.85)$ for customer knowledge [47], and the five-item scale $(\alpha=0.93)$ for advertising effect evaluation [46]. The single-item mode was used for the degree of familiarity of the Woniu brand (i.e., "Do you know the Woniu brand"?).

The five-item scaling method was used for the control test. The results of emotional and rational appeals were $M$ emotional appeal $=2.91$ vs. $4.02, F=9.7, p<0.05 ; M$ rational appeal $=2.43$ vs. $3.86, F=5.9, p<0.05$, which all had significant differences. The results of company- and consumeroriented information were $M$ company $=3.12$ vs. 4.33, $F=7.3, \quad p<0.05 ; \quad M$ consumer $=3.40$ vs. $4.56, \quad F=6.5$, $p<0.05$, which all had significant differences that prove the success of the experimental manipulation. For the emotional and rational appeal groups, the result of the customer knowledge test was $M=3.11$ vs. $4.02, F=2.7, p=1.08$, and the evaluation result of the advertising effect was $M=3.51$ vs. 3.02, $F=1.2, p=4.28$. There was no significant difference between the two control variables. The awareness rate of the Woniu brand was at $3 \%$, so the virtual brand had little influence on the result.

3.1.3. Results Analysis. An independent sample T-test was carried out on two groups of data of emotional and rational appeals. The results showed that the psychological ownership of the emotional appeal group was significantly higher than that of the rational appeal group ( $M$ emotional appeal $=3.76, M$ rational appeal $=2.27, t=6.34, p<0.05)$. The participation willingness of the emotional appeal group was also significantly higher than that of the rational appeal group $(M$ emotional appeal $=3.82, M$ rational appeal $=3.18$, $t=3.59, p<0.05)$. The relevant results supported the viewpoints of $\mathrm{H} 1$ and $\mathrm{H} 2$. The psychological ownership was grouped by means $(M$ mean $=3.04)$, and the data within one standard deviation were removed. A T-value comparison was made on participation willingness. The results showed that there was a significant difference between the willingness of the customers from both groups to participate in innovation, $t=7.56, p<0.05$, which supported H3. The above results also prove the interaction among advertising appeals, psychological ownership, and participation willingness.

A bootstrap program was used to test the mediating effect of insider identity perception. The sample size was 5000. At a $95 \%$ confidence interval, the mediating test results of psychological ownership did not include 0 (LLCI $=0.02$, $\mathrm{ULCI}=0.35$ ) and was significant with an effect size of 0.39 . After controlling psychological ownership, it was observed that advertising appeals still had a significant effect on 
participation intention $(\beta=0.19, p<0.05)$. The effect size decreased by 0.20 , indicating that psychological ownership played a partial mediating role, which supported $\mathrm{H} 4$.

To further verify the moderating effect of expression, an ANOVA analysis was carried out on psychological ownership under different advertising appeals. The results showed that the interaction between advertising appeals and expression was significant, $F(2,98)=6.85, p<0.05$. When the advertisement had emotional appeal, the score of the psychological ownership of the company-oriented information group was significantly lower than that of the consumer-oriented information group ( $M$ emotional appeal-company-oriented $=3.26 ; M$ rational appeal - consumer-oriented $=4.08, F=6.67, p<0.05$ ). When advertising had rational appeal, the score of the psychological ownership of the company-oriented information group was significantly lower than that of the consumer-oriented information group $(M$ rational appeal-consumeroriented $=3.25>M$ emotional appeal - company-oriented $=$ $2.72, F=3.25, p<0.05)$. The specific data are shown in Table 2, which presented above support H5.

The five hypotheses have been verified from the experimental data. The first is that advertising appeals and expression will affect consumers' willingness to participate in collaborative consumption. Compared with the rational appeal, the emotional appeal of advertising is more consistent with the values advocated by collaborative consumption, which has a positive impact on consumer participation. When the expression is consumer-oriented information, the impact on consumers will be greater. The second is the psychological mechanism of consumer participation. Contrary to common sense, the internal mechanism of a collaborative consumption scenario which emphasizes the right to use is still the change of psychological ownership. For consumers, the sharing economy is only the change of market manifestation, which is the difference of scenario variables in the research. However, as the consumer psychological decision-making mechanism, it has not been affected. The third is the mediating role of psychological ownership. The influence of advertising appeals on consumers will be affected by many factors, and psychological ownership is only one of them. In the literature on advertising appeals, variables such as customer expectation and cognitive fluency may also play a mediating role.

The background of research 1 is the tourism service industry. Due to the intangible characteristics of the service itself, consumers pay more attention to the right to use the service than the right to use the product. Consumers also relatively accept the collaborative consumption model more easily. Therefore, research 2 used the collaborative consumption of shared products to further demonstrate the hypotheses of the paper.

\subsection{Research 2}

3.2.1. Research Design and Subjects. The content of research 2 is consistent with that of research 1 and still applied the control group experimental method, and the collaborative consumption scenario used the shared picture book library. The external validity of the conclusion can be effectively improved by using products for experiments. At the same time, children's picture book is a product that customers choose very carefully. The experiment scene would have a stronger supporting effect on the hypothesis. The advertising materials were taken from real advertisements of companies related to picture books sharing, and the form of pictures and words used by these companies were adopted. The main reasons for choosing this scenario are as follows. First, with the improvement of living standards, picture books are gradually recognized by many parents in family education. Second, as the picture book sharing industry rapidly develops, all kinds of picture book libraries are very common in large- and medium-sized cities in China. Third, picture books involve children's education, which is not only a hotspot in the development of the education market, but also the focus of parents' attention.

Due to the particularity of the audience of picture books, the researcher did not choose children as subjects, but parents which are consumer decision makers. Participants were recruited through three kindergartens in Wuhan City, Hubei Province. For the research, 108 parents were recruited as participants. After the test, all participants would receive a picture book worth 15 yuan. Most of the children's educational consumption choices are completed by parents, so parents are explicitly required to participate. Among the subjects aged 22 to $48,32 \%$ were males and $68 \%$ were females. To avoid the deviation caused by different sources of students, all subjects of each kindergarten were randomly divided into four groups. The participants completed the experiment in a separate classroom before the children were picked up from school in the afternoon.

To avoid revealing the purpose of the experiment to the subjects and affecting the effect of the experiment, a virtual company named "Starlit Sky Picture Book Library" was created. Its advertising content is adapted from that of the Quxiaopiao Picture Book Sharing Platform, Liangmiao Picture Book Library, Yingtao Picture Book Library, Old John Picture Book Library, and other companies. Similar to research 1, the advertising content of the above companies was divided into emotional and rational appeals. The content related to emotion mainly included the concern of sharing, company, and relationship (e.g., "the neighbors' children are here," "the founder of the concept of picture book sharing," "changing three generations with reading," "reading together with parents, growing up with children," "looking for a dazed afternoon," "meeting picture books, achieving various possibilities," and "sowing the seeds of happiness together"). The content related to rationality mainly included convenience, credit mechanism, abundant book sources, and other services ("borrow and return," "combination of online and offline," "only select excellent picture books," "all the books you want to read are available here," and " $100000+$ mom's choice"). Experimental materials were adapted according to the actual advertisement. The relevant information is shown in Table 3.

The processing method of highlighting the contrast effect of the experiment was consistent with that of research 1 . In advertisements emphasizing company-oriented information, the company name "Starlit Sky Picture Book" was 
TABLE 2: Moderation of advertising information expression (research 1).

\begin{tabular}{lcc}
\hline \multirow{2}{*}{ Type } & \multicolumn{2}{c}{ Psychological ownership } \\
& Emotional appeals & Rational appeals \\
\hline $\begin{array}{l}\text { Company-oriented } \\
\text { information } \\
\begin{array}{l}\text { Consumer-oriented } \\
\text { information }\end{array}\end{array}$ & $3.26(22)$ & $3.25(25)$ \\
\hline
\end{tabular}

appropriately enlarged. In those emphasizing consumer-oriented information, the appellation of "baby" to consumers was appropriately enlarged. In advertisements that emphasized emotional appeal, photos of starry skies and seed growth were used as the background. In those which emphasized rational appeal, classical picture books and picture book library address distribution photos were used as the background.

In the experiment, the researcher told the subjects that they were recruited to do a customer survey to open a picture book library in the city. The initial content included a brief introduction of the company, including its development history, main business, scale, service guarantee, and other similar information. The relevant content was also adapted for the introduction of real companies. The company profile was followed by advertisements and then the questionnaire. To avoid revealing the real purpose of the experiment, the questionnaire was also interspersed with statements like "What brand of picture book library do you know?", "Your baby's weekly reading time," "What kind of picture books your baby is most interested in?", and other market research items. There were 11 questionnaires rejected due to incomplete or incorrect information and 97 valid questionnaires were obtained.

The main content of the questionnaire is consistent with that of research 1, including research variables of psychological ownership and participation willingness. The control variables included customer knowledge, advertising effectiveness evaluation, "Starlit Sky" brand familiarity, perceived risk, and parents' education level. Perceived risk was taken as a control variable due to the importance of children's education. Additionally, taking the difference of parents' perception of risk will directly affect consumption decisionmaking. Parent's educational level was taken as the control variable mainly because the acceptance of picture books is increasing in China, but it is still largely affected by parents' education level.

3.2.2. Control Test. All the scales used the mature items in the literature. Among them, the five-item scale $(\alpha=0.87)$ [44] was used for the two kinds of advertising appeals, the single-item mode for advertising expression [38], the sevenitem scale $(\alpha=0.83)$ for psychological ownership [45], the five-item scale $(\alpha=0.79)$ for participation willingness [46], the five-item scale $(\alpha=0.85)$ for customer knowledge [47], the five-item scale $(\alpha=0.93)$ for advertising effect evaluation, and the five-item scale ( $\alpha=0.83$ ) for perceived risk. The education level was directly compared with parents' educational level. The single-item mode was used for the degree of familiarity with the Starlit Sky brand (i.e., "Do you know the Starlit Sky brand?").

The five-item scaling method was used for the control test. The results of emotional and rational appeals were $M$ emotional appeal $=2.89$ vs. $3.77, F=4.7, p<0.05 ; M$ rational appeal $=2.36$ vs. $3.54, F=6.7, p<0.05$, which all had significant differences. The results of company- and consumeroriented information were $M$ company $=2.98$ vs. 4.02, $F=4.9, \quad p<0.05 ; M$ consumer $=3.12$ vs. $4.33, \quad F=8.2$, $p<0.05$ ), which all had significant differences, proving that the experimental manipulation was successful. For the emotional and rational appeal groups, the results of the customer knowledge test were $M=3.26$ vs. $3.98, F=3.1$, $p=0.74$. The evaluation result of the advertising effect was $M=2.88$ vs. $3.31, F=2.3, p=1.33$, and the result of perceived risk was $M=3.08$ vs. $2.68, F=7.2, p=3.36$. There was no significant difference in the above control variables. For the parents' educational backgrounds, $14.5 \%$ were graduates or above, $68.4 \%$ were university education, $12.8 \%$ were senior high school or technical secondary school education, and $4.3 \%$ were junior high school and other education. The scores of the above levels of educational attainment were four to one, and the results showed that there was no significant difference between various groups. The awareness rate with the Starlit Sky brand was $4.7 \%$, so the virtual brand had little influence on the result.

3.2.3. Results Analysis. The independent sample T-test was carried out on two groups of data of emotional and rational appeals. The results showed that the psychological ownership of the emotional appeal group was significantly higher than that of the rational appeal group ( $M$ emotional appeal $=3.47, M$ rational appeal $=2.66, t=4.38, p<0.05)$. Further, the participation willingness of the emotional appeal group was significantly higher than that of the rational appeal group $(M$ emotional appeal $=3.73, M$ rational appeal=3.09, $t=4.17, p<0.05)$. The relevant results supported the viewpoints of $\mathrm{H} 1$ and $\mathrm{H} 2$.

The psychological ownership was grouped by means $(M$ mean $=3.11$ ), and the data within one standard deviation were removed. A $T$-value comparison was made on the participation willingness. The results showed that there was a significant difference between the willingness of the two groups of customers to participate in innovation, $t=6.35$, $p<0.05$, which supported the viewpoint of $\mathrm{H} 3$. The above results also prove the interaction among advertising appeals, psychological ownership, and participation willingness. A bootstrap program was used to test the mediating effect of insider identity perception [48]. The sample size was 5000. At $95 \%$ confidence interval, the mediating test results of psychological ownership did not include 0 (LLCI $=0.14$, $\mathrm{ULCI}=0.46$ ) and was significant, with the effect size being 0.32. After controlling psychological ownership, it was observed that advertising appeal still had a significant effect on participation willingness $(\beta=0.17, p<0.05)$, and the effect size decreased by 0.15 , indicating that psychological ownership played a partial mediating role, which supported $\mathrm{H} 4$. 
TABLe 3: Main text contents of experimental materials (research 2).

\begin{tabular}{lcc}
\hline Type & Company-oriented information & Consumer-oriented information \\
\hline $\begin{array}{l}\text { Emotional } \\
\text { appeals }\end{array}$ & $\begin{array}{c}\text { "Starlit Sky" sow the seeds of happiness for babies: sharing } \\
\text { environmental protection, reading growth, and creating } \\
\text { infinite possibilities. }\end{array}$ & $\begin{array}{c}\text { "Starlit Sky" invites babies to sow the seeds of happiness } \\
\text { together: sharing environmental protection, reading growth, } \\
\text { and creating infinite possibilities. }\end{array}$ \\
\hline $\begin{array}{l}\text { Rational } \\
\text { appeals }\end{array}$ & $\begin{array}{c}\text { "Starlit Sky" builds a library around your babies. Provide } \\
\text { home delivery service, select carefully, and have rich sources } \\
\text { of books. }\end{array}$ & $\begin{array}{c}\text { "Starlit Sky" invites babies to build a library around them. } \\
\text { Provide home delivery service, select carefully, and have rich } \\
\text { sources of books. }\end{array}$ \\
\hline
\end{tabular}

To further verify the moderating effect of expression, an ANOVA analysis was carried out on psychological ownership under different advertising appeals. The results showed that the interaction between advertising appeals and expression was significant, $F(2,99)=5.28, p<0.05$. When advertising used emotional appeal, the score of psychological ownership of the company-oriented information group was significantly lower than that of the consumer-oriented information group ( $M$ emotional appeal-company-oriented =3.21; $M$ emotional appeal-consumeroriented $=4.12, F=3.71, p<0.05)$. When advertising used rational appeal, the score of psychological ownership of the company-oriented information group was significantly lower than that of the consumer-oriented information group ( $M$ rational appeal-company-oriented $=3.89>M$ rational appeal-consumer-oriented $=2.50, F=4.34, p<0.05)$. The above data are shown in Table 4 , which presented above support H5.

From the experimental data, the relevant hypotheses have also been verified in the field of shared products. From the experimental process, there are still several points worthy of attention. First, the consumption of picture books is special. Although parents as decision makers generally participate in the whole process when purchasing picture books, it is still a product that separates consumers from decision makers. In addition, children occupy a special position in Chinese families. The above characteristics may affect the judgment of the subjects, and there may be a certain gap between the participation willingness and the actual market. Second, the mediating effect of psychological ownership may be stronger. Compared with children, parents will have a more rational view of consumption, which can better separate the right to use and the right of possession. However, from the perspective of children, the connection with products will lead to stronger psychological ownership, and the mediating effect may be stronger. Third, advertising is not the best way to promote the sharing of picture books. Consumers are highly involved in the products and services related to children's education. Advertising is more about information release. From the influence of advertising design on participation willingness, there is still some distance between attitude and behavior. In comparison with advertising, the actual market effect of personal promotion and word-of-mouth communication will be more effective.
TABLE 4: Moderating of advertising information expression (research 2).

\begin{tabular}{lcc}
\hline \multirow{2}{*}{ Type } & \multicolumn{2}{c}{ Psychological ownership } \\
& Emotional appeals & Rational appeals \\
\hline $\begin{array}{l}\text { Company-oriented } \\
\text { information }\end{array}$ & $3.21(24)$ & $3.89(25)$ \\
$\begin{array}{l}\text { Consumer-oriented } \\
\text { information }\end{array}$ & $4.12(26)$ & $2.50(24)$ \\
\hline
\end{tabular}

\section{Discussion}

In terms of theoretical contribution, there are three main points. First, the concepts related to the sharing economy are further clarified. This study discusses collaborative consumption close to the market, highlighting the essential characteristics of the impact of a sharing economy on the market. Second, it expands the research field of advertising appeal. It is of certain theoretical value to extend the research of advertising appeals to the field of collaborative consumption. Third, it reveals the psychological mechanism of consumers in sustainable consumption. The common sense of sustainable consumption, especially in a sharing economy, generally thinks that the right to use is more important than ownership, and the advantages of sustainable consumption also come from the worship of the right to use. However, as observed from the research, the right to use cannot replace ownership. The recognition and involvement of customers on collaborative consumption rely more on the promotion of psychological ownership.

From the perspective of practical value, the first is that collaborative consumption companies should pay attention to the promotion of customer psychological ownership. Companies can strengthen their connection with customers on the aspects of consumption link design and customer interaction to enhance customers' recognition of companies. The second is the choice of advertising appeals and information of collaborative consumption companies. When designing advertisements, companies should adopt more emotional appeals to realize the combination of philosophy and culture between customers and companies. Furthermore, companies should release more consumer-oriented information, enhance consumers' sense of participation, and guide more consumers to choose company products or services. 


\section{Conclusions}

Two experiments were conducted to demonstrate the hypotheses. It is believed that in the process of collaborative consumption based on sustainable tourism consumption, advertising appeals will affect participation willingness through psychological ownership. At the same time, the expression of advertising information will moderate the relationship between advertising appeals and psychological ownership.

Although this study discusses market phenomena and theories, conducts experimental research with the background of tourism and picture books, and supports relevant hypotheses, it still has some deficiencies in the research process. The first is that the research did not take price into account. As collaborative consumption is a new market phenomenon, price is extremely important as the threshold of consumption. Moreover, price may have a cross effect with the advertising appeal, which is often referred to in the market as "pay for the feelings." The second is that the research sample is still limited. There are many industries involved in the sharing economy. This study only chooses tourism and picture books in the analyses, and the externality of the research conclusion can still be further strengthened. The third is that part of the mediating effect shows that there may be other mediating factors between advertising appeals and participation willingness, including company positioning, brand impression, and more. Future research can verify the research hypotheses with multiple industries and diverse samples and explore the psychological mechanism of consumer participation around collaborative consumption.

\section{Data Availability}

The data are available from the corresponding authors upon request.

\section{Conflicts of Interest}

The authors declare that there are no conflicts of interest regarding the publication of this paper.

\section{Acknowledgments}

This research study was supported by the National Natural Science Foundation of China (Grant nos. 71672053 and 71772141), Projects of the National Social Science Foundation of China (Grant no. 20BGL091), and Philosophy and Social Science Research Key Project of Education Department of Hubei Province (Grant no. 19D091).

\section{References}

[1] S. J. Lawson, M. R. Gleim, R. Perren, and J. Hwang, "Freedom from ownership: an exploration of access-based consumption," Journal of Business Research, vol. 69, no. 8, pp. 2615-2623, 2016.

[2] J. Xiang, "Why timesharing becomes a scam in China," 2016, http://www.mafengwo.cn/travel-news/200136.html.
[3] J. Liao and Z. Cui, "Sharing economy brings four changes," 2017, http://toutiao.manqian.cn/wz_1nfZxAr7Xn.html.

[4] S. Dawkins, A. W. Tian, A. Newman, and A. Martin, "Psychological ownership: a review and research agenda," Journal of Organizational Behavior, vol. 38, no. 2, 2015.

[5] T. Schaefers, K. Wittkowski, S. Benoit, and R. Ferraro, "Contagious effects of customer misbehavior in access-based services," Journal of Service Research, vol. 19, no. 1, pp. 3-21, 2016.

[6] J. Xiao, "Our Media in the Era of Sharing Economy Should be Played in This Way," 2015, http://business.sohu.com/ 20150713/n416655094.shtml.

[7] K. Hellwig, F. Morhart, F. Girardin, and M. Hauser, "Exploring different types of sharing: a proposed segmentation of the market for "sharing" businesses," Psychology \& Marketing, vol. 32, no. 9, pp. 891-906, 2015.

[8] J. Hamari, M. Sjöklint, and A. Ukkonen, "The sharing economy: why people participate in collaborative consumption," Journal of the Association for Information Science and Technology, vol. 67, no. 9, pp. 2047-2059, 2016.

[9] R. Jenkins, M. Molesworth, and R. Scullion, "The messy social lives of objects: inter-personal borrowing and the ambiguity of possession and ownership," Journal of Consumer Behaviour, vol. 13, no. 2, pp. 131-139, 2014.

[10] S. Jin, J. Yang, E. Wang, and J. Liu, "The influence of highspeed rail on ice-snow tourism in northeastern China," Tourism Management, vol. 78, Article ID 104070, 2020.

[11] R. Belk, "Sharing," Journal of Consumer Research, vol. 36, no. 5, pp. 715-734, 2010

[12] J. L. Pierce, T. Kostova, and K. T. Dirks, "The state of psychological ownership: integrating and extending a century of research," Review of General Psychology, vol. 7, no. 1, pp. 84-107, 2003.

[13] I. Jussila, A. Tarkiainen, M. Sarstedt, and J. F. Hair, "Individual psychological ownership: concepts, evidence, and implications for research in marketing," Journal of Marketing Theory \& Practice, vol. 23, no. 2, pp. 121-139, 2015.

[14] R. Belk, "You are what you can access: sharing and collaborative consumption online," Journal of Business Research, vol. 67, no. 8, pp. 1595-1600, 2014.

[15] R. Botsman and R. Rogers, What's Mine Is Yours: The Rise of Collaborative Consumption, Harper Business, New York, NY, USA, 2010.

[16] C. P. Lamberton and R. L. Rose, "When is ours better than mine? A framework for understanding and altering participation in commercial sharing systems," Journal of Marketing, vol. 76, no. 4, pp. 109-125, 2012.

[17] B. Buczynski, Sharing is Good: How to Save Money, Time and Resources through Collaborative Consumption, New Society Publishers, British Columbia, Cananda, 2013.

[18] R. Botsman and R. Rogers, "Beyond zipcar: collaborative consumption," Harvard Business Review, vol. 88, no. 10, 2010.

[19] T. Hennig-Thurau, V. Henning, and H. Sattler, "Consumer file sharing of motion pictures," Journal of Marketing, vol. 71, no. 4, pp. 1-18, 2007.

[20] B. Walsh, Today's Smart Choice: Don't Own. Share, Time International, New York, NY, USA, 2011.

[21] P. A. Albinsson and B. Yasanthi Perera, "Alternative marketplaces in the 21st century: building community through sharing events," Journal of Consumer Behaviour, vol. 11, no. 4, pp. 303-315, 2012.

[22] L. K. Ozanne and P. W. Ballantine, "Sharing as a form of anticonsumption? An examination of toy library users," Journal of Consumer Behaviour, vol. 9, no. 6, pp. 485-498, 2010. 
[23] H. Jacob, O. Chezy, and R. Matti, "Advertising appeals, moderators, and impact on persuasion," Journal of Advertising Research, vol. 57, no. 3, pp. 305-318, 2017.

[24] R. W. Preiss, B. M. Gayle, N. Burrell, M. Allen, and J. Bryant, Mass Media Effects Research: Advances through Meta-Analysis, L. Erlbaum Associates, Mahwah, NJ, USA, 2007.

[25] D. J. Moore, W. D. Harris, and H. C. Chen, "Affect intensity: an individual difference response to advertising appeals," Journal of Consumer Research, vol. 22, no. 2, pp. 154-164, 1995.

[26] A. Y. Lee, P. A. Keller, and B. Sternthal, "Value from regulatory construal fit: the persuasive impact of fit between consumer goals and message concreteness," Journal of Consumer Research, vol. 36, no. 5, pp. 735-747, 2010.

[27] S. Okazaki, B. Mueller, and C. R. Taylor, "Global consumer culture positioning: testing perceptions of soft-sell and hardsell advertising appeals between U.S. and Japanese consumers," Journal of International Marketing, vol. 18, no. 2, pp. 20-34, 2010.

[28] S. Kazakova, V. Cauberghe, L. Hudders, and C. Labyt, "The impact of media multitasking on the cognitive and attitudinal responses to television commercials: the moderating role of type of advertising appeal," Journal of Advertising, vol. 45, no. 4, pp. 403-416, 2016.

[29] G. Daomeng, Z. Yang, Z. Liyi, W. Xuan, and Y. Cong, "Conformity feedback in an online review helpfulness evaluation task leads to less negative feedback-related negativity amplitudes and more positive P300 amplitudes," Journal of Neuroscience, Psychology, and Economics, vol. 12, no. 2, pp. 73-87, 2019.

[30] C. K. W. De Dreu and D. V. Knippenberg, “The possessive self as a barrier to conflict resolution: effects of mere ownership, process accountability, and self-concept clarity on competitive cognitions and behavior," Journal of Personality and Social Psychology, vol. 89, no. 3, pp. 345-357, 2005.

[31] C. P. Kirk, S. D. Swain, and J. E. Gaskin, "I'm proud of it: consumer technology appropriation and psychological ownership," Journal of Marketing Theory \& Practice, vol. 23, no. 2, pp. 166-184, 2015.

[32] J. L. Pierce, T. Kostova, and K. T. Dirks, "Toward a theory of psychological ownership in organizations," The Academy of Management Review, vol. 26, no. 2, pp. 298-310, 2001.

[33] L. V. Dyne and J. L. Pierce, "Psychological ownership and feelings of possession: three field studies predicting employee attitudes and organizational citizenship behavior," Journal of Organizational Behavior, vol. 25, no. 4, pp. 439-459, 2004.

[34] J. A. G. Folse, J. G. Moulard, and R. D. Raggio, "Psychological ownership: a social marketing advertising message appeal?" International Journal of Advertising, vol. 31, no. 2, pp. 291-315, 2012.

[35] N. Bendapudi and R. P. Leone, "Psychological implications of customer participation in Co-production," Journal of Marketing, vol. 67, no. 1, pp. 14-28, 2003.

[36] K. Kim, Y. Cheong, and J. S. Lim, "Choosing the right message for the right cause in social cause advertising: type of social cause message, perceived company-cause fit and the persuasiveness of communication," International Journal of Advertising, vol. 34, no. 3, pp. 473-494, 2015.

[37] S. Jack, "Selling virtue: pandering ad campaigns from chevron, starbucks, liberty Mutual,and barak obama," 2009, http://www.slate.com/articles/news_and_politics/ press_box/2009/01/selling_virtue.html.
[38] M. E. Drumwright, "Company advertising with a social dimension: the role of noneconomic criteria," Journal of Marketing, vol. 60, no. 4, pp. 71-87, 1996.

[39] I. W. Hung and R. S. Wyer, "Shaping consumer imaginations: the role of self-focused attention in product evaluations," Journal of Marketing Research, vol. 48, no. 2, pp. 381-392, 2011.

[40] M. Sujan, J. R. Bettman, and H. Baumgartner, "Influencing consumer judgments using autobiographical memories: a self-referencing perspective," Journal of Marketing Research, vol. 30, no. 4, pp. 422-436, 1993.

[41] L. L. Jacoby and C. M. Kelley, "An episodic view of motivation: unconscious influences of memory," in Handbook of Motivation and CognitionGuilford Press, New York, NY, USA, 1990.

[42] J. S. Johar and M. J. Sirgy, "Value-expressive versus utilitarian advertising appeals: when and why to use which appeal," Journal of Advertising, vol. 20, no. 3, pp. 23-33, 1991.

[43] T. S. Han, H. H. Chiang, T. C. Melewar, and A. Chang, "A multilevel investigation of relationships among brand-centered HRM, brand psychological ownership, brand citizenship behaviors, and customer satisfaction," European Journal of Marketing, vol. 46, no. 5, pp. 626-662, 2012.

[44] L. A. N. Xu, "Why do customers participate in creation?, "Themotivation of consumers to participate in creation"," Acta Psychologica Sinica, vol. 39, no. 2, pp. 343-354, 2007.

[45] L. R. Flynn and R. E. Goldsmith, "A short, reliable measure of subjective knowledge," Journal of Business Research, vol. 46, no. 1, pp. 57-66, 1999.

[46] B. J. Calder, E. C. Malthouse, and U. Schaedel, "An experimental study of the relationship between online engagement and advertising effectiveness," Journal of Interactive Marketing, vol. 23, no. 4, pp. 321-331, 2009.

[47] R. N. Stone and K. Grønhaug, "Perceived risk: further considerations for the marketing discipline," European Journal of Marketing, vol. 27, no. 3, pp. 39-50, 1993.

[48] A. F. Hayes, "Introduction to mediation, moderation, and conditional process analysis: a regression-based approach," Journal of Educational Measurement, vol. 51, no. 3, pp. 335337, 2013. 